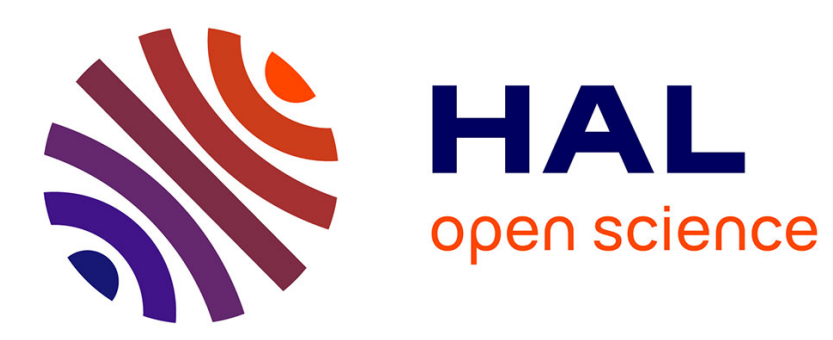

\title{
Error Compensation in Indoor Positioning Systems based on Software Defined Visible Light Communication
}

\author{
Antonio Costanzo, Valeria Loscrì
}

\section{To cite this version:}

Antonio Costanzo, Valeria Loscrì. Error Compensation in Indoor Positioning Systems based on Software Defined Visible Light Communication. Physical Communication, 2019, 34, pp.235-245. 10.1016/j.phycom.2019.04.002 . hal-02087506

\section{HAL Id: hal-02087506 https://hal.science/hal-02087506}

Submitted on 2 Apr 2019

HAL is a multi-disciplinary open access archive for the deposit and dissemination of scientific research documents, whether they are published or not. The documents may come from teaching and research institutions in France or abroad, or from public or private research centers.
L'archive ouverte pluridisciplinaire HAL, est destinée au dépôt et à la diffusion de documents scientifiques de niveau recherche, publiés ou non, émanant des établissements d'enseignement et de recherche français ou étrangers, des laboratoires publics ou privés. 


\title{
Error Compensation in Indoor Positioning Systems based on Software Defined Visible Light Communication
}

\author{
A. Costanzo ${ }^{\text {a }}$, V. Loscri ${ }^{\mathrm{a}}$ \\ ${ }^{a}$ INRIA Lille-Nord Europe, 40 Avenue du Halley, Villeneuve d'Ascq, 59650, France
}

\begin{abstract}
Visible Light Communication (VLC) paradigm allows the reusing of existing illuminating infrastructures in order to provide data communication. VLC can be considered a promising technology also for positioning in indoor environments, due to its potentially high accuracy and low costs. However, the main obstacle to the use of VLC for localization purposes is the high level of environmental noises, mainly due to sunlight. A novel approach, for easily measuring environmental noises and compensating their effects on localization results performed by an Indoor Positioning System (IPS) based on VLC, is proposed in this work. Frequency Division Multiplexing (FDM) is adopted to divide the total bandwidth into a series of non-overlapping frequency sub-bands corresponding to each signal, while an estimation of Signal to Noise Ratio (SNR), obtained through real time Power Spectral Density measurements in the proper frequency ranges, is exploited to compensate the error in positioning due to sunlight and other wideband external optical disturbing signals. The proposed approach has been validated through experimental tests, carried out using a simple deployment of low power lamps, low cost hardware and a software defined approach. In the region under test, receiver position has been experimentally detected with higher accuracy in comparison to classical FDM approach, confirming the correctness and effectiveness of our proposed technique. In order to further validate the proposed approach, an additive measurement campaign has been successfully carried out considering a scenario characterized by very low SNR levels.
\end{abstract}

\section{Introduction}

Visible Light Communication (VLC) is an emerging technology, belonging to optical wireless communications, that can be developed by the means of low cost Light Emitting Diodes (LED) for providing wireless data transmission. This paradigm focuses on the exploitation of light sources normally used for illumination purposes. Even if this approach sounded as futuristic and overly ambitious, with few research teams interested up to last decade, in recent years, VLC started to attract several academic groups and industrial companies.

One of the main reason in this interest, by both research and commercial point of view, is due to the progressive replacement of incandescent and fluorescent lamps by LEDs. Compared to traditional light sources, indeed, LEDs show several advantages, like long life expectancy, high lighting efficiency, and no out-of-visible-band optical spectrum which could significantly damage the eyes (lamps based on incandescent radiation present a significant infrared spectrum and fluorescent lamps show an additional ultraviolet range). Differing from incandescent and fluorescent sources, light produced by LED can be modulated with a higher blinking frequency, allowing the communication system the achievement of impressive data rates, potentially up to some GB/s. VLC paradigm can soon offer extremely low cost communication and power consumption, a large unlicensed bandwidth and ubiquitous reuse of existing infrastructures, opening the possibility to several attractive applications.

Light Fidelity (Li-Fi) paradigm (1) foresees a high speed bi- directional fully connected, visible light wireless communication system, analogous to $\mathrm{Wi}-\mathrm{Fi}$, which can provide extremely high data rates, assuring connectivity in those environments where radio frequencies (RF) are not allowed, like in particular units in hospitals, mines or petrochemicals plants. Furthermore, since RF are strongly absorbed by water, VLC represents a reasonable solution in order to provide an effective and reliable underwater wireless communication (2). Another interesting potential application is the exploitation of the received signal from LED sources for IPS $(3 ; 4 ; 5)$. The characteristics of optical wireless signal itself, in addition to the ubiquity of LED lamps in almost all indoor environments, allow higher precision without a significant amount in terms of overall costs and complexity (2). A rapid diffusion of VLC positioning, however, is strongly limited by the effect of environmental noise (mainly sunlight) on system performances.

The main contributions of the paper can be summarized as follows:

- Theoretical derivation of the noise power impact on distance detection based on a generic trilateration algorithm.

- Exploitation of proposed theoretical analysis for reducing positioning error due to noisy optical signal in RSSI based Visible Light IPS.

- A simple prototyping, following an ad-hoc Software Defined approach, and experimental validation in real operative scenarios, according to different external light conditions, maintaining a good accuracy even under high noisy conditions(low SNR). 
In particular, the paper is structured as follows. A brief state of art on IPS, particularly focused on VLC localization, is presented in 2, for contextualizing our contribution in existing literature. The Section 3 describes the proposed architecture. In Section 4, a mathematical model, describing how to estimate the noise in the system, is presented. In Section 5 the experimental setup is shown and experimental results are discussed. Finally, we conclude the paper in Section 6.

\section{Related Works and Main Contributions}

IPS are becoming very popular, for their great potentiality in modern ubiquitous networks. The possibility of tracking a device, and consequently a user, with a certain accuracy, open a huge range of possible novel applications in the field of Internet of Things. Real time monitoring of travelers in airports or in rail stations, for instance, could provide a custom planning on the basis of the best path for flight or train connections, shops and other services. In the same way, an accurate indoor positioning can ensure a safe evacuation during a fire or a flood of a building, the control of the number of people and their position inside a restricted area or a custom best path in a museum on the basis of a group of piece of art at which a user is particularly interested on.

Several different technologies have been exploited for allowing indoor positioning (6), based on ultrasound (7), infrared, radars $(8 ; 9 ; 10)$, etc. However, a poor trade-off between accuracy, flexibility and scalability of the these architectures, overall cost and size of the devices, prevent to achieve a wide diffusion of indoor positioning in the market. In order to exploit existing infrastructures and reduce costs, Wi-fi (11) Bluetooth (12) and RFID systems $(13 ; 14)$, are widely considered in current literature; however, the accuracy performed by Wi-Fi (15) (some meters) is too low for most of potential indoor applications. Positioning systems based on Bluetooth show a high latency, which represents a problem in real time applications. Positioning systems based on RFID technology need numerous infrastructure components, installed and maintained in the working area. In this sense, VLC (1) represents one of the most attractive approaches for indoor positioning, due to the high achievable accuracy, low costs of the devices and the possibility of reusing existing infrastructures for both lighting and positioning (16). In addition, long time life, high energy efficiency and low maintenance feeds of LED lamps, are consistent with a predictable commercial diffusion in next years (17). Several works have been carried out on this topic, following different approaches (a recent in-depth description is provided in (18)), mainly validated through numerical simulations or measurements in an ideal scenario, in which artificial and natural disturbing light sources do not affect system accuracy. In order to distinguish the signal incoming from different transmitters, both Time Division Multiplexing (TDM) and Frequency Division Multiplexing (FDM) can be employed. However, in (19) is shown how even small errors in synchronization may have a great impact in terms of positioning errors. A significant effort in indoor positioning using visible light, in which frequency allocation is successfully exploited, has been provided in (20), achieving an excellent accuracy. However, results obtained in (20), refer to ideal external light conditions. Indeed, few works deal with experimental results in a real environment and most of them are based on fingerprinting approaches. Moreover, data collection at the off-line training stage is quite time-consuming and sudden changes in natural light conditions during the day could completely prevent a correct detection. A noise estimation has been carried out in (21) where experimental tests successfully validated the proposed approach. However, the use of auxiliary devices, in this case an accelerometer, significantly impacts on the complexity of the overall architecture. Another significant contribution, using a smart-phone camera, is described in (22), where an accuracy of $7 \mathrm{~cm}$ has been achieved without auxiliary devices. However, the use of sophisticated signal generators in transmitting stage, increase the overall costs and limits the scalability of the system. In this paper, we propose a VLC IPS, based on low-cost components and a flexible architecture. A detailed analysis of environmental noise, according to a software defined based signal processing approach, allowed the achievement of interesting results in terms of accuracy, without complicating the architecture of the system. A novel approach based on real time monitoring and correction of environmental noise in the scenario has been exploited in order to compensate errors even in low Signal to Noise Ratio (SNR) conditions.

\section{Software Defined VLC Positioning System}

A simplified scheme of our low cost illuminating-positioning architecture, describing transmitting light devices is shown in Fig. 1. A power line network feeds all the components of the system in the transmitting stage, namely the lamps and the LED drivers, that are composed of a micro-controller and few other hardware components (resistances and transistors). Warm white single LEDs are chosen for better providing illumination purposes and lamp blinking is controlled in order to generate signals at different frequencies, allowing the receiver to distinguish beams from different transmitters. We propose a modified version of a Frequency Division Multiplexing technique (FDM), including dedicated channels for environmental noise monitoring. The main operations performed by the Software Defined Visible Light Indoor Positioning System are resumed in the block diagram in Fig. 2.

In particular, receiving path operations are summarized as follows:

Optical signal is detected, pre-filtered and amplified using a proper combination of a photo-diode and a trans-impedance amplifier. Analog to digital conversion, buffering and timing are performed by a low cost single board micro-controller, following the approach adopted by the authors in (23), (24). This operation is necessary in order to avoid loss of timing due to the limited capacity of the board. The received signal is properly digitized, all further operations are performed by software, in order to allow a low cost and flexible architecture, following a software defined paradigm.

Signal is sort out in three different paths, each one estimating power coming from a different transmitter; each path, in- 


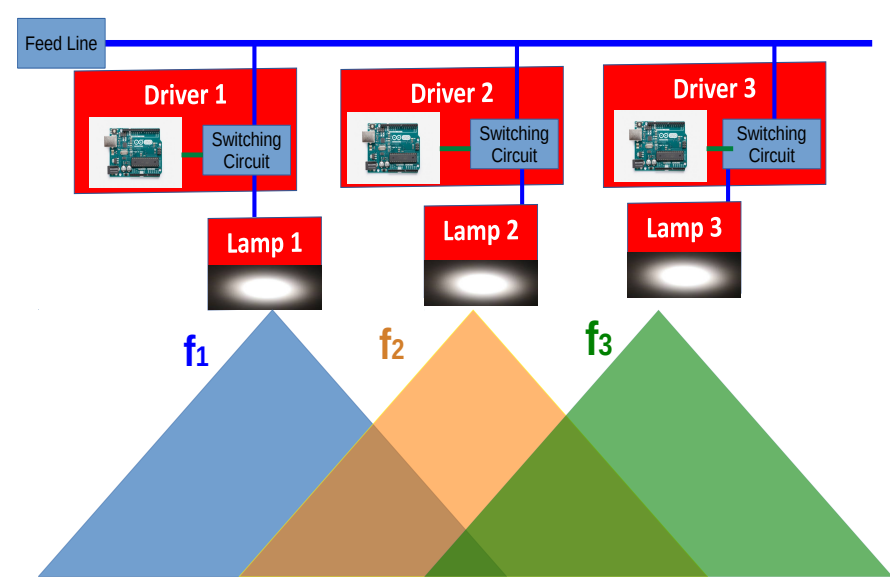

Figure 1: Architecture of the VLC positioning and illuminating transmitting system.

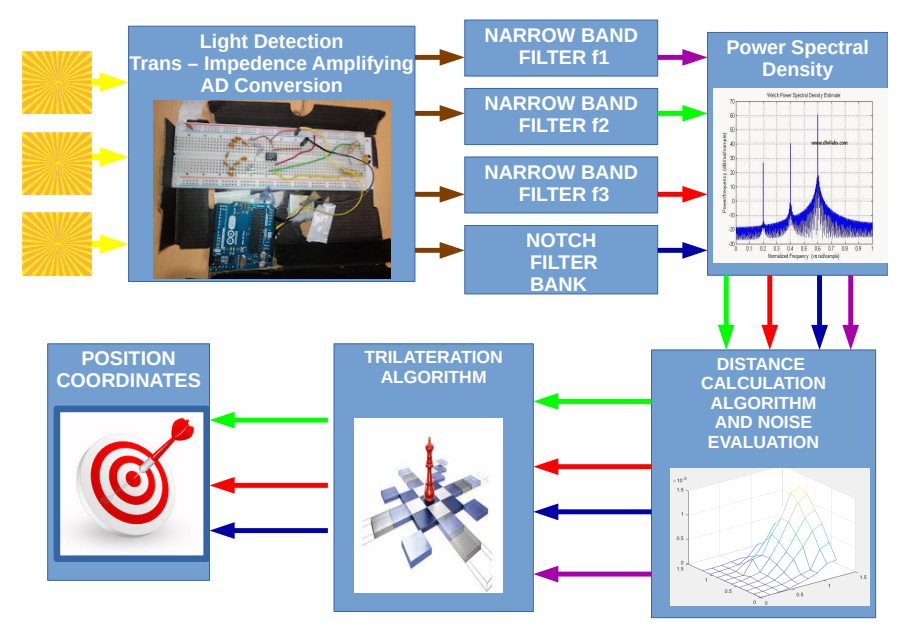

Figure 2: Main operations of the VLC positioning and illuminating receiving system.

deed contains a high $\mathrm{Q}$ factor peak filter for eliminating contributions due to the other transmitters. A fourth additional path (representing a major contribution in this architecture) is implemented in order to roughly evaluate environmental noise affecting the system. The signals are filtered through notch filters and then Power Spectral Density is dynamically calculated and integrated in proper frequency ranges in order to determinate power contributions coming from illuminating sources and providing a noise estimation, using a Frequency Division Multiplexing (FDM) approach. An initial calibration of the system is performed, properly initializing a priori information about power, radiation pattern and position of each LED, about photo-diode gain, field of view and responsivity. An estimation of the distance between each transmitter and the receiver is performed, evaluating Received Signal Strength Indicator (RSSI) measured for each stage, and properly considering optical channel characteristics. Measured noise values in the fourth stage are properly processed in order to mitigate the error of measured distances between each transmitter and the receiver. Corrected distance values are given in input to a trilateration algorithm for estimating the position of the receiver.

A detailed explanation about channel modeling, power measurements and RSSI analysis, proposed noise correction and final positioning algorithm, are provided in Section 4.

\section{Indoor positioning in a noisy environment}

In this section we detail the distance estimation of each transmitter and the receiver to be localized and then we explain our approach to reduce the noise component to improve the localization accuracy.

\subsection{Distance Estimation}

As briefly described in the previous section, , received power values, corresponding to each received signal $\left(P_{r 1}, P_{r 2}\right.$ and $\left.P_{r 3}\right)$ are calculated as following:

$$
\begin{aligned}
& P_{r 1}=\int_{f 1-\frac{f_{1}}{Q_{1}}}^{f 1+\frac{f_{1}}{Q_{1}}} \operatorname{PSD}\left[x_{1}(t)\right] d f \\
& P_{r 2}=\int_{f 2-\frac{f_{2}}{Q_{3}}}^{f 2+\frac{f_{2}}{Q_{2}}} \operatorname{PSD}\left[x_{2}(t)\right] d f \\
& P_{r 3}=\int_{f 3-\frac{f_{3}}{Q_{3}}}^{f 3+\frac{f_{3}}{Q_{3}}} \operatorname{PSD}\left[x_{3}(t)\right] d f
\end{aligned}
$$

where $x_{r 1}(t), x_{r 2}(t)$ and $x_{r 3}(t)$ are time domain signals after acquisition, amplifying, conditioning and filtering. $Q_{1}, Q_{2}$ and $Q_{3}$ are the quality factors of peak filters and the operator PSD[.] indicates Power Spectral Density of the signal. The ratio between the optical radiated power in the main direction $P_{T o p t}$, and the received optical power at a certain distance $d$ can be modeled by considering the LED as a Lambertian source. Indeed, assuming $-3 \mathrm{~dB}$ beam width of the LED equal to $\phi_{-3 d B}$, received power can be calculated as follows (25):

$$
P_{\text {Ropt }}=P_{\text {Topt }} \frac{(m+1) A}{2 \pi d^{2}} \cos ^{m}(\phi) T(\psi) g(\psi)
$$

being:

- $A$ the effective area of the photodiode;

- $d$ the distance between transmitter and receiver;

- $\phi$ the angle of irradiance with respect to the axis normal to the transmitter surface;

- $\psi$ the angle of incidence with respect to the axis normal to the receiver surface;

- $T(\psi)$ the gain of optical filter;

- $G(\psi)$ the receiver optical concentrator gain;

- $m$ the order of the Lambertian Radiation 
In particular, Lambertian order is calculated as follows

$$
m=\frac{\ln 2}{\ln \left(\cos \left(\phi_{-3 d B}\right)\right)}
$$

while the gain of the optical concentrator can be calculated, starting by its refraction index $\eta$ and by the field of view of the receiver $\psi_{0}$, as follows:

$$
G(\psi)=\frac{\eta^{2}}{\sin ^{2}\left(\psi_{0}\right)}
$$

The relation between electrical measured power and optical received power depends on the responsivity $R_{p}$ and the area $\mathrm{A}$ of the photo-diode. A further calibrating factor $\xi$ is introduced for taking into account trans-impedance gain of the remaining hardware front-end and other effects at the receiving side. In particular, the relation $\zeta$ between optical power $P_{\text {opt }}$ and electrical power $P_{e l}$ can be calculated as follow:

$$
\zeta=\frac{P_{e l}}{P_{\text {opt }}}=\frac{R_{p} \xi}{A}
$$

The distances $d_{1}, d_{2}$ and $d_{3}$ between each transmitter and the receiver are so estimated by measured power at the receiver and optical transmitted power $P_{\text {Topt }}$ after each processing phase as:

$$
\begin{aligned}
& d_{1}^{*}=\sqrt{\frac{(m+1) A \zeta \cos ^{m} P_{\text {Topt }}(\phi) T(\psi) g(\psi)}{2 \pi \int_{f 1-\frac{f_{1}}{Q_{1}}}^{f 1+\frac{f_{1}}{Q}} P S D\left[x_{1}(t)\right] d f}} \\
& d_{2}^{*}=\sqrt{\frac{(m+1) A \zeta \cos ^{m} P_{T o p t}(\phi) T(\psi) g(\psi)}{2 \pi \int_{f 2-\frac{f_{2}}{Q_{2}}}^{f 2+\frac{f_{2}}{Q_{2}}} P S D\left[x_{2}(t)\right] d f}} \\
& d_{3}^{*}=\sqrt{\frac{(m+1) A \zeta \cos ^{m} P_{T o p t}(\phi) T(\psi) g(\psi)}{2 \pi \int_{f 3-\frac{f_{3}}{Q_{3}}}^{f 3+\frac{f_{3}}{Q_{3}}} P S D\left[x_{3}(t)\right] d f}}
\end{aligned}
$$

Received signals $x_{1}(t), x_{2}(t)$ and $x_{3}(t)$, considered into 8, 9 and 10 for distance detection are filtered in and integrated in a narrow band, in order to strongly reduce interference due to other artificial light sources in the scenario. However, a significant amount of noise affecting the detection is due to sunlight and other wide-band source noise in scenario. In addition, signal components reflected in the environment, further complicate a fair distance detection. In this work, the problem of non line of sight transmission is not yet faced, however some interesting approaches can be exploited in a future extension of this work, following, for example, the one proposed in (26).

\subsection{Noise Estimation}

In this work we propose a novel method to take into account real time noise variations, based on power measurement outside LEDs operative bandwidth (see the fourth path shown in Fig. 2). In particular, a series of notch filters, centered in blinking frequencies of transmitting lamps, have been used in order to estimate and isolate the noise contribution outside the operative bandwidths. Since both thermal noise and sunlight incident power affect the system in the wide-band of a visible light frontend, all the spectral noise components outside the transmitting ranges are integrated in order to provide an estimation of total noise in the system.

We need to consider that the transmitters work in a very narrow band, and this make possible to consider an average noise level outside the bandwidth. In particular, being $x_{N}(t)$ the noise component measured after filtering transmitting source signal (the fourth stage in Fig. 2), and $B$ the total bandwidth of the system, the estimation of overall environmental noise, $N_{\text {out }}$, is calculated as follows:

$$
\begin{aligned}
N_{\text {out }}= & \int_{0}^{f 1-\frac{f_{1}}{Q_{1}}} \operatorname{PS} D\left[x_{N}(t)\right] d f+\int_{f 1+\frac{f_{1}}{Q_{1}}}^{f 2-\frac{f_{2}}{Q_{2}}} \operatorname{PS} D\left[x_{N}(t)\right] d f+ \\
& +\int_{f 2+\frac{f_{2}}{Q_{2}}}^{f 3-\frac{f_{3}}{Q_{3}}} \operatorname{PSD}\left[x_{N}(t)\right] d f+\int_{f 3+\frac{f_{3}}{Q_{3}}}^{B} \operatorname{PSD}\left[x_{N}(t)\right] d f
\end{aligned}
$$

Since, in this work, the amount of average noise has been supposed uniform in bandwidth, an indirect estimation of noise power in each corresponding transmitting range has been defined, starting by $N_{\text {out }}$, evaluating noise level in each bandwidth, namely:

$$
N_{r i}=\frac{2 f_{i}}{Q_{i} B} N_{\text {out }}\left(1+\frac{\sum_{k=1}^{n} \frac{2 f_{k}}{Q_{k}}}{B}\right)
$$

being $i$ the index of each transmitter, $n$ the number of transmitters (in our case $(n=3)), \frac{2 f_{i}}{Q_{i}}$ its corresponding frequency range of the received signal, while the term $N_{\text {out }}\left(1+\frac{\sum_{k=1}^{n} \frac{2 f_{k}}{Q_{k}}}{B}\right)$, represents the total estimated noise in the overall device receiving range. This latter term, multiplied by the ratio between the bandwidth of the $i^{\text {th }}$ transmitter and the bandwidth of the overall system (namely $\frac{2 f_{i}}{B Q_{i}}$ ), represents an indirect estimation of the noise affecting $i^{\text {th }}$ path. Once the estimated noise for each path has been calculated, signal to noise ratio for each frequency range can be simply calculated as the ratio between useful power $P_{r i}^{*}$ over measured noise, namely:

$$
S N R_{i}=\frac{P_{r}^{*}}{N_{r i}}=\frac{P_{r i}-N_{r i}}{N_{r i}}
$$

A simple reference system, for analytically evaluating and correcting the effect of the noise in Visible Light Positioning, has been considered and shown in Fig. 3, where the receiver is located in the plane xy, at a distance $d_{1}, d_{2}$ and $d_{3}$ by the transmitters.

The relation between the distance $d_{i}^{*}$, calculated without compensating the noise (and derived in (8), (9) and (10)) and the distance $d_{i}$, considering noise compensation, can be derived as follows. From (4) and (7) one can obtain, :

$$
\cos ^{m}\left(\phi_{i}\right)=\frac{2 \pi d_{i}^{* 2} P_{r i}^{*}}{(m+1) A \zeta P_{T o p t}(\phi) T(\psi) g(\psi)}
$$




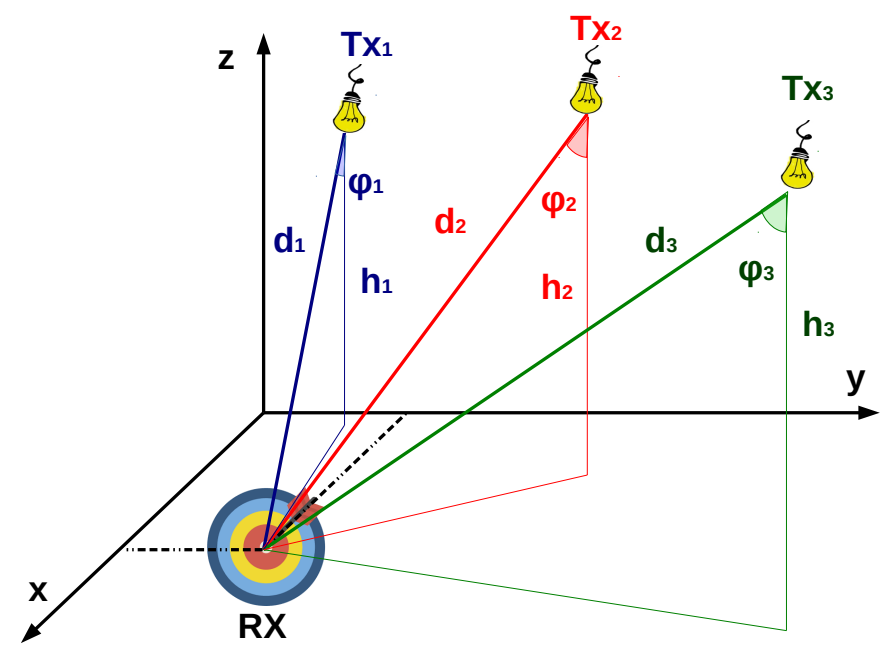

Figure 3: Reference system

$$
\frac{h_{i}^{m}}{d_{i}^{* m}}=\frac{2 \pi d_{i}^{* 2} P_{r i}^{*}}{(m+1) A \zeta P_{\text {Topt }}(\phi) T(\psi) g(\psi)}
$$

and finally we obtain

$$
d_{i}^{*}=\left(\frac{h_{i}^{m}(m+1) A \zeta P_{T o p t}(\phi) T(\psi) g(\psi)}{2 \pi P_{r i}^{*}}\right)^{\frac{1}{m+2}}
$$

According to (16), the real distance $d_{i}$ in presence of noise, can be alternatively expressed as:

$$
d_{i}=\left(\frac{h_{i}^{m}(m+1) A \zeta P_{\text {Topt }}(\phi) T(\psi) g(\psi)}{2 \pi P_{r i}}\right)^{\frac{1}{m+2}}
$$

and the relative error $\Delta d_{i}$ between real and ideal distances, can be expressed as in (18).

$$
\Delta d_{i}=1+\frac{d_{i}}{d_{i}^{*}}=1-\left(\frac{P_{r i}}{P_{r i}^{*}}\right)^{-\frac{1}{m+2}}
$$

Replacing (13) into (16), the final expression for the relative error, is described in (19).

$$
\Delta d_{i}=1-\left(1+\frac{1}{S N R}\right)^{-\frac{1}{m+2}}
$$

Since each value of $d_{i}$ represents an input in the trilateration algorithm, a simple estimation on the error of these values based on a prediction of the environment can dramatically improve system performance. For example, an important characteristic to evaluate for the design of a visible light indoor positioning system, according to (19), is the order of Lambertian Radiation, and consequently, the $-3 \mathrm{~dB}$ beam-width of the transmitting LED. According to this formulation, an evaluation of relative error $\Delta d_{i}$, has been shown in Fig. 4 for different values of SNR and different LED beam widths.

In Fig. 4 one can notice, in presence of the same Signal to Noise Ratio level, how a narrow beam radiation pattern shows better performance in terms of input distance error than a large

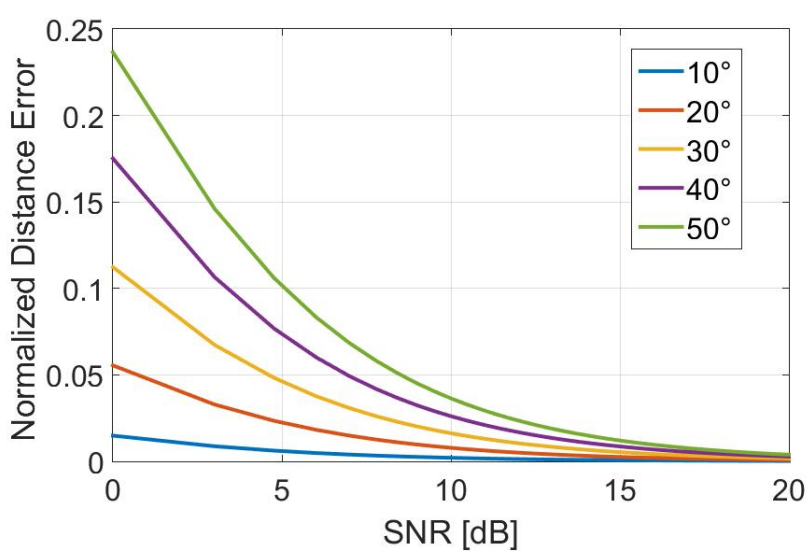

Figure 4: Relative error of distances between TX and RX in presence of noise for different values of transmitting LED beam-width

one. However, a narrow beam width covers a narrow area in terms of useful radiated power, and consequently, in terms of SNR itself. A trade-off between LEDs characteristics and their deployment in the scenario, according to noise condition, is so necessary for guaranteeing good performances. Once the input error is determined, it is taken into account in the positioning algorithm in order to evaluate, and eventually correct final errors in positioning.

\subsection{The Trilateration Algorithm}

In this section we show how we use the classical formulation of the trilateration problem for positioning a generic receiver by integrating the approach presented in the previous sections.

In particular, being $\mathrm{x}, \mathrm{y}$ and $\mathrm{z}$ the unknown coordinates of the receiver, $x_{i}, y_{i}$ and $z_{i}$ the known coordinates of the $i^{\text {th }}$ transmitter, one can write:

$$
\left\{\begin{array}{l}
\left(x-x_{1}\right)^{2}+\left(y-y_{1}\right)^{2}+\left(z-z_{1}\right)^{2}=d_{1}^{2} \\
\left(x-x_{2}\right)^{2}+\left(y-y_{2}\right)^{2}+\left(z-z_{2}\right)^{2}=d_{2}^{2} \\
\left(x-x_{3}\right)^{2}+\left(y-y_{3}\right)^{2}+\left(z-z_{3}\right)^{2}=d_{1}^{3}
\end{array}\right.
$$

which, can be written in the matrix form $A \boldsymbol{x}=\mathbf{b}$, where:

$$
\begin{gathered}
A=\left[\begin{array}{llll}
1 & -2 x_{1} & -2 y_{1} & z_{1} \\
1 & -2 x_{2} & -2 y_{2} & z_{2} \\
1 & -2 x_{3} & -2 y_{3} & z_{3}
\end{array}\right] \\
x=\left[\begin{array}{c}
x^{2}+y^{2}+z^{2} \\
x \\
y \\
z
\end{array}\right] \\
b=\left[\begin{array}{c}
d_{1}^{2}-x_{1}^{2}-x_{2}^{2}-x_{3}^{2} \\
d_{2}^{2}-y_{1}^{2}-y_{2}^{2}-y_{3}^{2} \\
d_{3}^{2}-z_{1}^{2}-z_{2}^{2}-z_{3}^{2}
\end{array}\right]
\end{gathered}
$$

Several techniques have been developed for solving this non linear system, in this work we refer to the algebraic solution for trilateration and multilateration proposed in (27). In particular, we introduced in the algorithm the input error defined in (19), and we compute the error of the estimated position. Being 
$\boldsymbol{x}^{*}=\left[x^{*}, y^{*}, z^{*}\right]$ the vector of receiver position, without taking effect of environmental noise, calculated using the vector $\boldsymbol{d}=\left[d 1^{*}, d 2^{*}, d 3^{*}\right]$ as theoretically defined in (8),(9) and (10), one can write

$$
A \boldsymbol{x}^{*}=\boldsymbol{b}^{*}=\left[\begin{array}{l}
d_{1}^{* 2}-x_{1}^{2}-x_{2}^{2}-x_{3}^{2} \\
d_{2}^{* 2}-y_{1}^{2}-y_{2}^{2}-y_{3}^{2} \\
d_{3}^{* 2}-z_{1}^{2}-z_{2}^{2}-z_{3}^{2}
\end{array}\right]
$$

The vector of correct receiver position $\boldsymbol{x}^{r}=\left[x^{r}, y^{r}, z^{r}\right]$, taking into account the effects of noise in the environment, can be written considering the definition in (19), and changing the distance vector as follows.

$$
A \boldsymbol{x}^{r}=\boldsymbol{b}^{\boldsymbol{r}}=\left[\begin{array}{c}
\left(1+\Delta d_{1}\right) d_{1}^{* 2}-x_{1}^{2}-x_{2}^{2}-x_{3}^{2} \\
\left(1+\Delta d_{2}\right) d_{2}^{* 2}-y_{1}^{2}-y_{2}^{2}-y_{3}^{2} \\
\left(1+\Delta d_{3}\right) d_{3}^{* 2}-z_{2}^{2}-z_{3}^{2}
\end{array}\right]
$$

The vector $\boldsymbol{x}_{\text {err }}=\left[x_{\text {err }}, y_{\text {err }}, z_{\text {err }}\right]$, representing the error (considering each coordinate) due to noise in the environment, can be simply estimated as the difference between these trilateration results, namely:

$$
x_{e r r}=x^{r}-x^{*}
$$

The module of the error vector, can be finally estimated as:

$$
\left|\boldsymbol{x}_{\text {err }}\right|=\left|\boldsymbol{x}^{r}-\boldsymbol{x}^{*}\right|=\sqrt{x_{\text {err }}^{2}+y_{\text {err }}^{2}+z_{\text {err }}^{2}}
$$

This formulation can be useful for simulating the effect of environmental noise given a particular topology of transmitters. These information can be exploited for the choice of features (in terms of radiating power and beam-width), position, heights and number of transmitting lamps for covering a particular scenario. The same approach does not lose generality if more than three transmitters are used.

A numerical example, considering the setup of Fig. 3, with identical transmitters (with beam-width equal to 10 degrees and transmitting optical power equal to $0.1 \mathrm{~W}$ ) located in the points $\boldsymbol{x}_{\mathbf{1}}=[21.5,113,120] \mathrm{cm}, \boldsymbol{x}_{\mathbf{2}}=[108,74,120] \mathrm{cm}$, and $\boldsymbol{x}_{\mathbf{3}}=[0,60,120]$ has been simulated using a constant noise floor of $-70 \mathrm{dBW}$ (however, in a realistic case, like the one we will consider in next section, a map of measured noise in each point of the space is provided in input to the algorithm). In this example, the receiver is constrained on the plane $z=0$. In Fig. 5 the estimated $\mathrm{x}$-component error in position detection on a $120 \times 120 \mathrm{~cm}$ surface on $\mathrm{z}=0$ plane is shown. Considering the same scenario, y-component error is shown in Fig. 6, while the module of error vector is presented in Fig. 7.

It can be noticed how the vector error map related to $\mathrm{x}$ component and the one related to y component do not assume the same values, so. In the design of the visible light positioning system all the components should be taken into account and not only the module of the error. In the setup considered in simulation, it is evident how the error in the region in the middle of the surface (in each map) is lower than in the peripheral areas, where one or more transmitters are far from the considered point. The position and the number of transmitting light, optical source power and the other parameters in receiving and

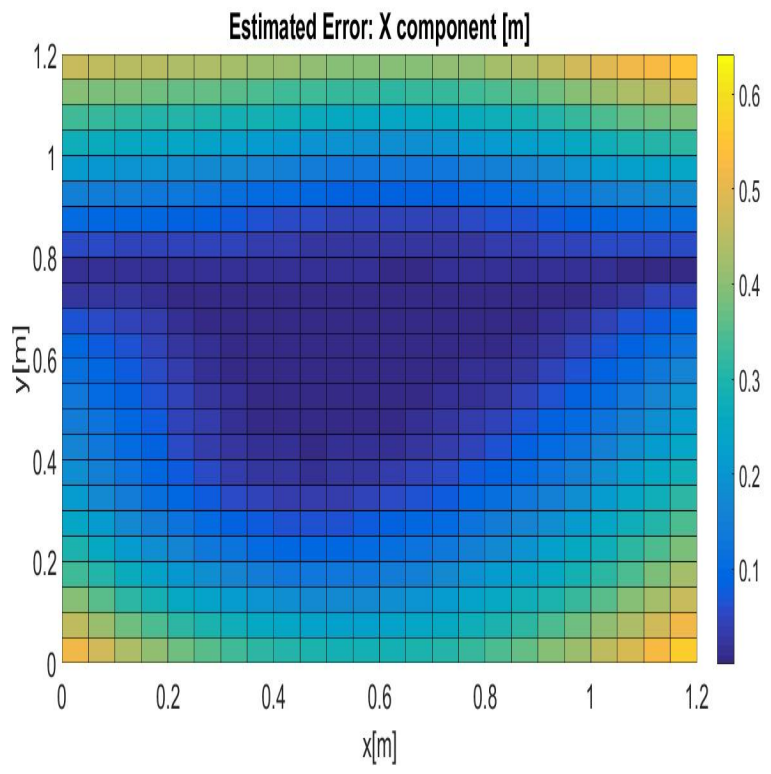

Figure 5: Estimated $\mathrm{x}$-component error in position detection in presence of a total noise equal to $\mathrm{N}=-70 \mathrm{dBW}$

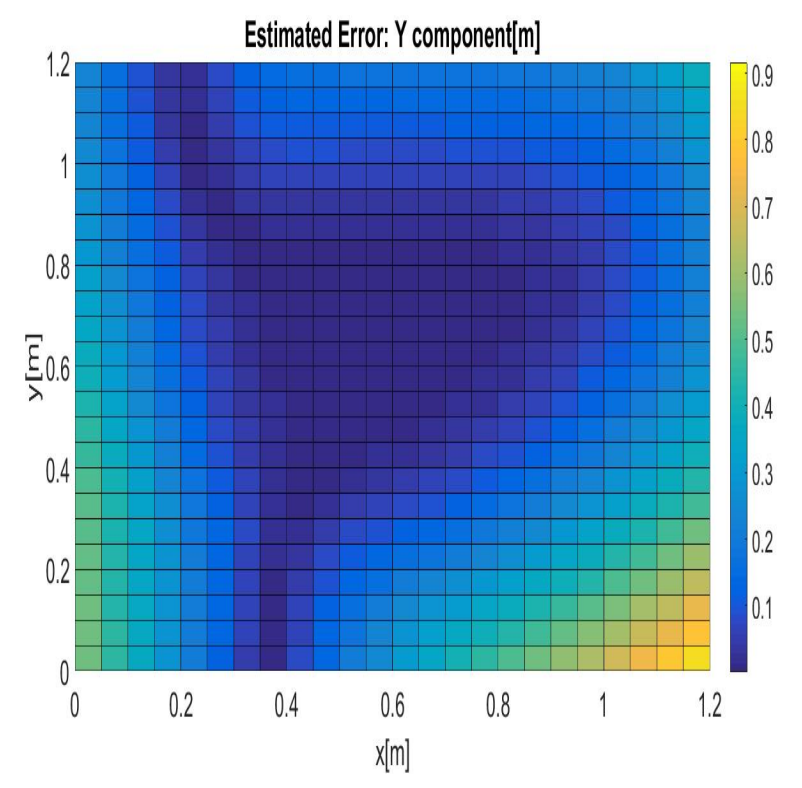

Figure 6: Estimated y-component error in position detection in presence of a total noise equal to $\mathrm{N}=-70 \mathrm{dBW}$ 


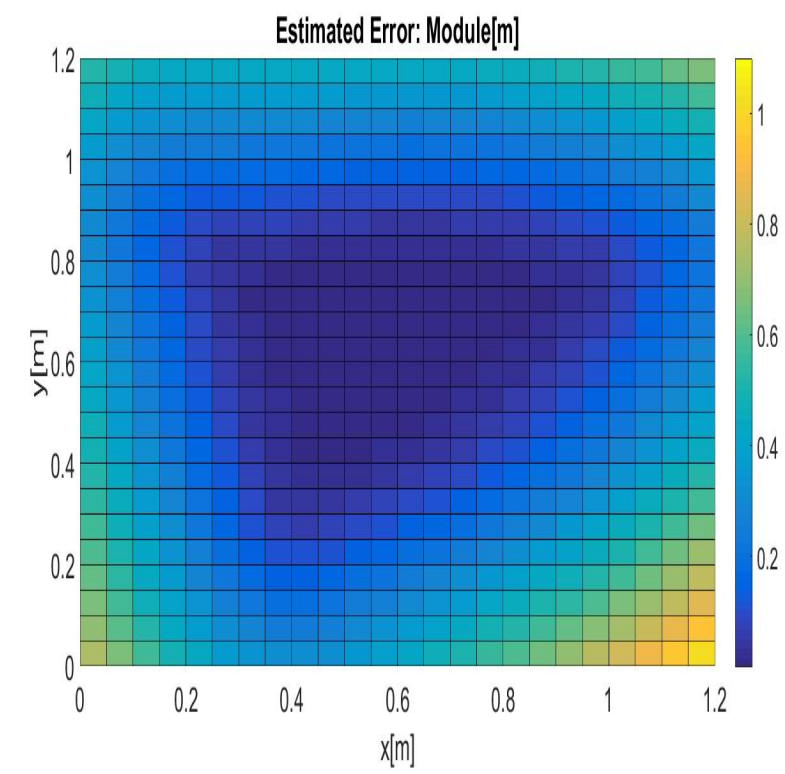

Figure 7: Estimated error module in position detection in presence of a total noise equal to $\mathrm{N}=-70 \mathrm{dBW}$

transmitting stage, could be easily chosen in order to maintain a certain degree of expected accuracy in a certain region, on the basis of external noise. Since only a simple algebraic analysis is necessary before giving in input distance values to a generic trilateration algorithm, our approach does not add any significant amount of complexity. The same configuration proposed in this section has been set up in two different real scenarios, which are presented in next section.

\section{Experimental validation}

An experimental setup, for validating the proposed visible light positioning approach, is provided in this section. In particular to the follow we provide a comparison between:

- simulations based on an ideal, uniform noise power in the xy plane equal to $N_{\text {out }}=-70 \mathrm{dBm}$, without applying the compensating technique for noise power;

- measurements with the proposed noise awareness approach without compensation of the noise power;

- measurements with the proposed noise awareness approach, where environmental noise level is measured in each point of the xy plane, simultaneously with the power associated to the transmitting blinking ranges, in order to compensate positioning errors, according to the description provided in previous sections.

Our VLC positioning system is constituted by three identical transmitters, each one composed by the following hardware components.

- A commercial warm white LED (XLamp MC-E warm, produced by CREE);
- An Arduino Uno board, generating the transmitting signal for driving the led.

- A driving circuit, composed by resistors and transistors.

- A power supply, feeding the led (operating voltage $12 \mathrm{~V}$ ) and the Arduino (operating voltage 5V).

The receiver is composed by the following hardware components:

- A commercial photodiode (OSD15-5T, fabricated by Centronic).

- A trans-impedance amplifying and pre-filtering circuit composed by a low cost operational amplifier (LTC1050), low cost resistors and capacitors.

- An Arduino board, for data acquisition and analog digital conversion.

\subsection{First Experimental Scenario}

A picture of the first experimental validation setup is proposed in Fig. 8, where the reference system is the same shown in Fig. 3, and the position of each transmitter is the same considered in the previous section. The Arduino Boards have been programmed before the test through a dedicated IDE and left in a stand alone configuration (since the waveform does not change during the experiment), while, in the receiving stage, a PC equipped with the commercial software LabView has been employed for developing the software defined architecture and the positioning operations.

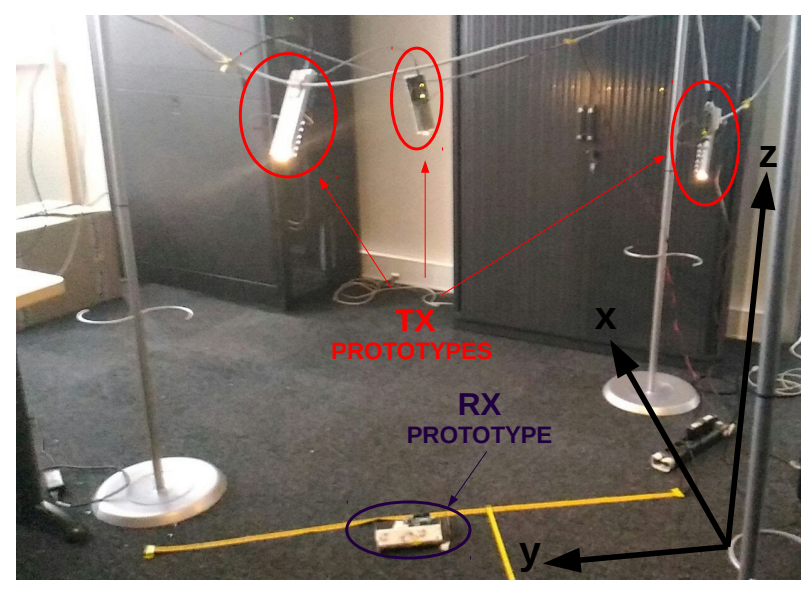

Figure 8: Experimental testbed of proposed VLC positioning and illuminating receiving system.

In order to consider a realistic environment, a normal office room ( $4 X 3 X 2.8$ meters) provided with a window has been considered as operative scenario. The receiver has been located on the floor, which represents the plane $\mathrm{z}=0$ and the transmitter are at an height of 1meter by the floor. Since multi-path and other NLOS components have not yet been considered in this analysis, obstacles in the central area of the room have been removed, while lateral object and the normal sunlight in Fig. 8 have been 
taken part of the measured scene for obtaining realistic results. Low frequency square waves, but guaranteeing no flickering problems $(125 \mathrm{~Hz}, 166.7 \mathrm{~Hz}$ and $200 \mathrm{~Hz})$ have been chosen for LED blinking. This choice has been done to avoid high performance micro-controllers in the transmitting stage and allow the possibility of using the proposed approach not only with LED, but even with fluorescent illuminating lights which allow very low switching between on and off period. In order to properly filter received signal, a quality factor equal to $70 \mathrm{~dB}$ has been set for each one of the peak filters in the transmitter ranges and the same value has been set for the notch filters in the noise evaluation path. The receiver has been placed on each point of a grid made up by 9x9 points, with an extension of 120x120 cm.

Power spectral density has been measured for each path, like shown in Fig. 9, Fig. 10 and Fig. 11 for the central frequency of each transmitter.

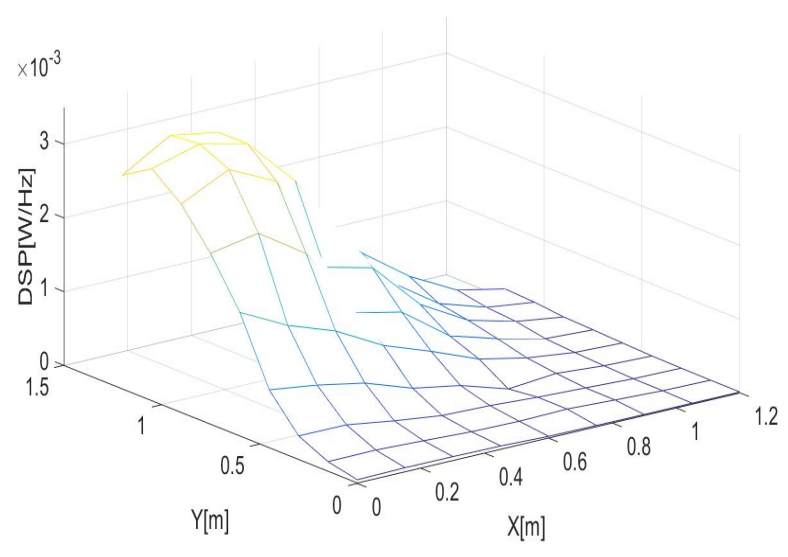

Figure 9: Measured Power Spectral Density for $\mathrm{f}=125 \mathrm{~Hz}$, corresponding to TX1, located in $\boldsymbol{x}_{\mathbf{1}}=[21.5,113,120] \mathrm{cm}$

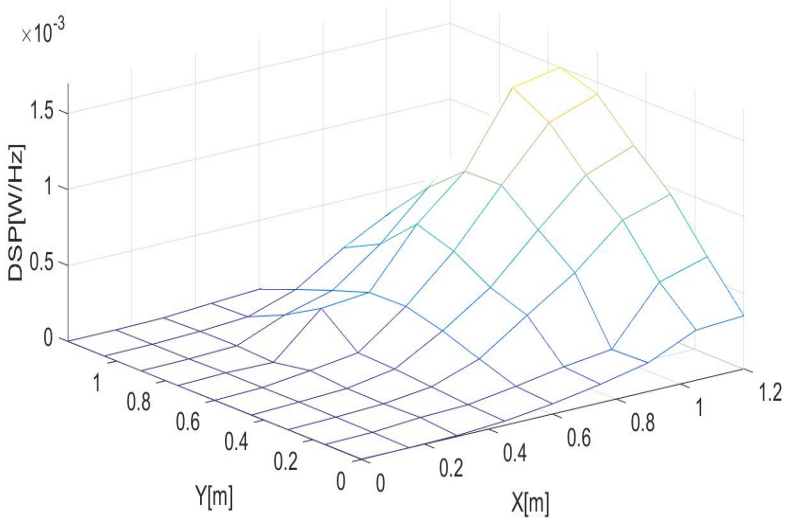

Figure 10: Measured Power Spectral Density for $\mathrm{f}=166.7 \mathrm{~Hz}$, corresponding to TX2, located in $\boldsymbol{x}_{\mathbf{2}}=[108,74,120] \mathrm{cm}$

Measured PSD have been integrated and related distance between each transmitter and the receiver have been calculated through the model described in previous section. According to the same formulation, noise level and the related measured signal to noise ratio have been determined for each test point in the

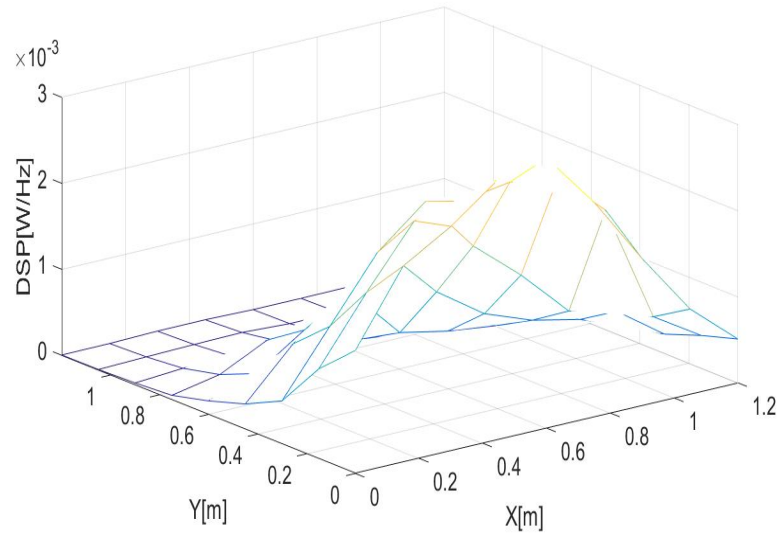

Figure 11: Measured Power Spectral Density for $\mathrm{f}=200 \mathrm{~Hz}$, corresponding to TX3, located in $\boldsymbol{x}_{\mathbf{3}}=[0,60,120] \mathrm{cm}$

plane xy. Measured noise has been exploited to calculate the expected error after the trilateration operation and to improve the accuracy of the receiver position.

Both compensated and uncompensated positions have been determined for each point of the grid in the xy plane and compared with the real position of the receiver, for evaluating the accuracy of the system. In Fig. 12 the module of error in both situations, as defined in (27) has been evaluated in the path from the point $[0,60,0]$ to the point $[120,0,0]$.

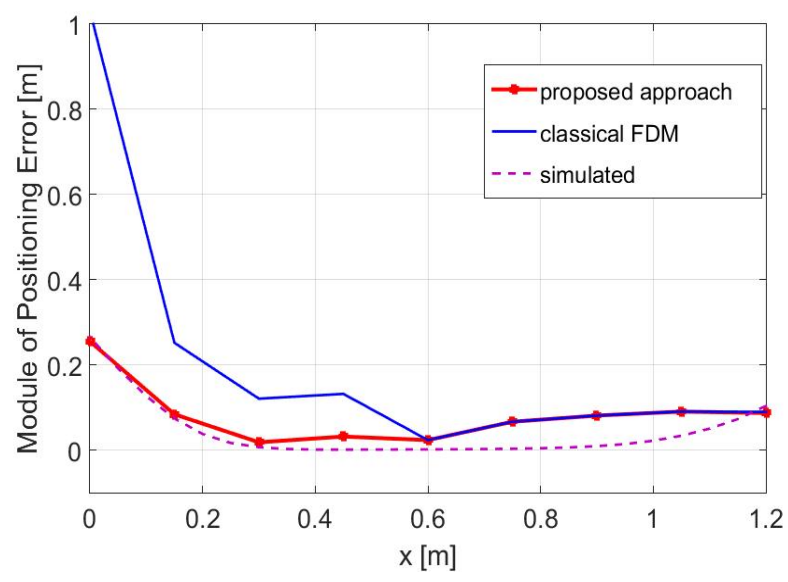

Figure 12: Error estimation of proposed VLC indoor positioning system in the path from the point $[0,60,0]$ to the point $[120,60,0]$

In the farthest area from the transmitters and in a position characterized by the presence of a high level of sunlight interference, a large error, preventing a correct detection, can be observed. However, applying the proposed compensation a significant error reduction has been achieved, mainly following simulated results. Indeed, the range in which the device is correctly detected introducing proposed noise aware approach, is sensitively stretched. In order to achieve a further validation, error in positioning, considering a path with a lower sunlight interference, from the point $[60,0,0]$ to the point $[60,120,0]$, has been considered in Fig. 13. Since this path is less "impacted" 


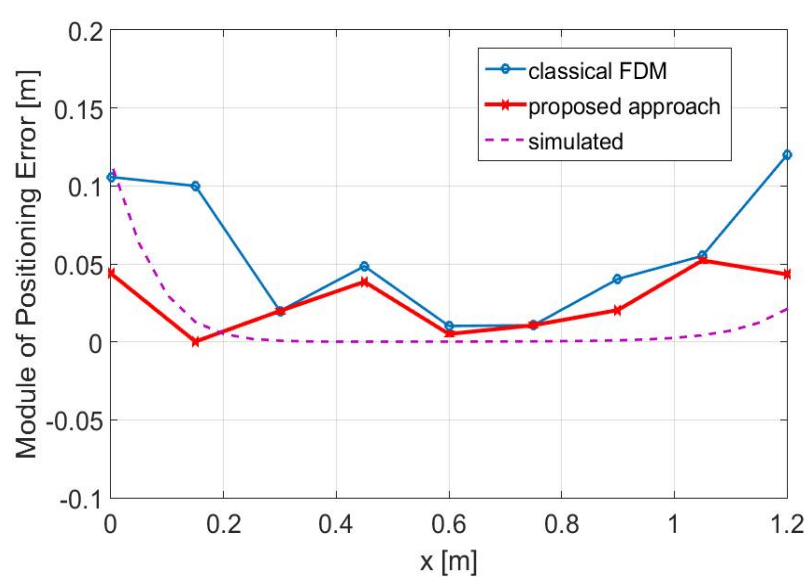

Figure 13: Average error of proposed VLC indoor positioning system in the path from the point $[60,0,0]$ to the point $[60,120,0]$

by sunlight interference, the overall error is lower than in the first case. However, also in this case, an appreciable reduction in positioning error is achieved. Indeed, in the peripheral areas of the scenario, where SNR is lower, noise compensation is more effective. In both paths, in the central area of the scenario, where reflections of the transmitting signal do not impact and a better useful illumination is provided, a higher accuracy has been achieved nonetheless the optical noise in the area, with a good agreement between simulations and measurements. Furthermore, in both the cases shown in Fig. 12 and Fig. 13, proposed compensation has reduced measured error in each test point, confirming the correctness of the proposed approach.

\subsection{Second Experimental Scenario}

In order to provide a further validation of the proposed Light Indoor Positioning technique in a more noisy environment another scenario has been considered as shown in Fig. 14.

In particular, we considered a practical use case, in which the position of an item (the receiver) on a table has to be detected using illuminating lamps (transmitters in Fig. 15).

The same components as in the previous experiment have been used, while the distance between the table and the ceiling is higher than the previous case and equal to $2 \mathrm{~m}$. Room dimensions are the same of the ones in the first experimental scenario. A correct positioning in this configuration is trickier than the previous one for two main reasons:

- The distance between transmitter and receiver is doubled into respect the first configuration and the environmental noise, coming from the windows, is much higher. So, the system operates in very low signal to noise ratio.

- The dark floor in the first setup does not allow the reflection of the signal, while, in the second setup, a shiny wooden table, highly reflecting, is considered as supporting surface. This configuration increases also multiple reflections, not only due to sunlight, but also due to the path transmitter-table-white ceiling-receiving.

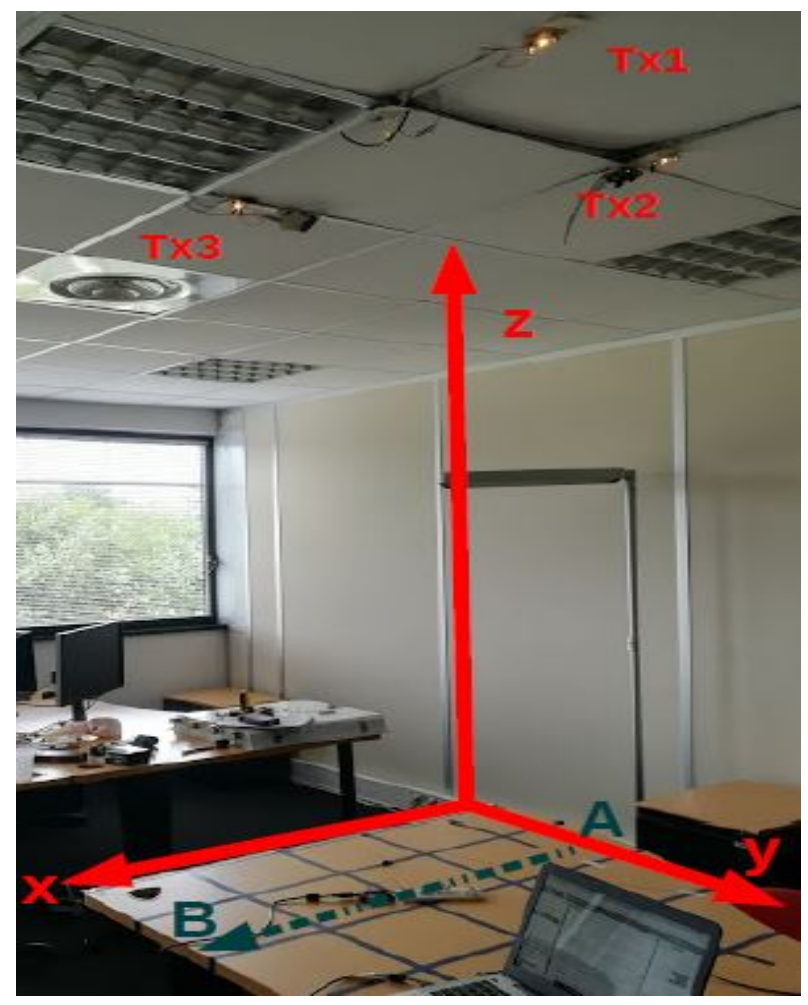

Figure 14: Experimental Tests in a real use case setup: Overall System

Considering this setup, a daily measurement campaign (from 8:00 to 20:00) has been carried out in a sunny day, with windows facing north in the North Hemisphere, sunrise at 5:53 and sunset at 21:36.

In particular, three measurement sessions of two hours have been carried out, where receiver position has been recorded each 15 minutes and a mean has been calculated for each session. In order to evaluate the effect of sunlight variation, Signal to Noise Ratio (SNR) at the beginning of each session is measured through the additive channel of proposed architecture and provided in Fig. 16, 17, and 18, considering one of the three transmitters.

It can be noticed how a very poor SNR is measured, especially in the areas near to the windows and farther from the

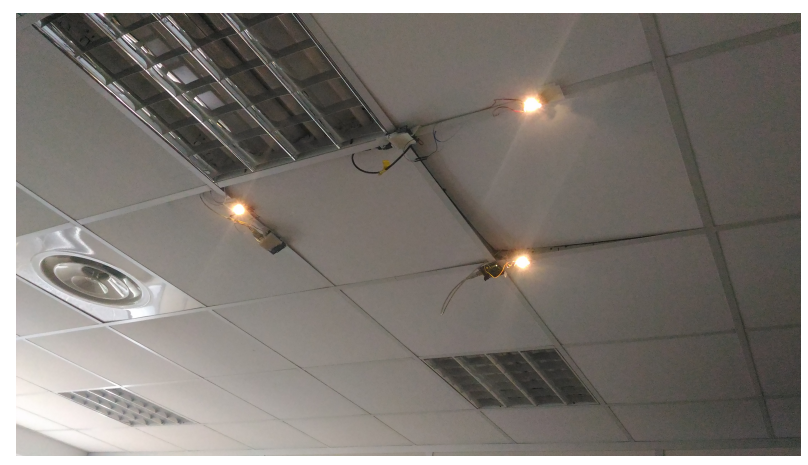

Figure 15: Experimental Tests in a real use case setup: Visible Light Communication Transmitters 


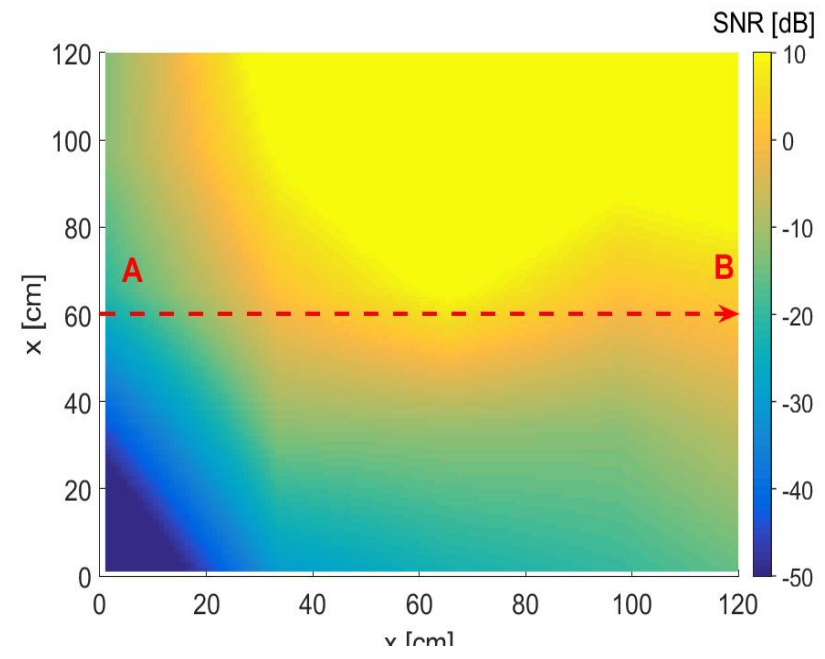

Figure 16: Averaged Measured Signal to Noise Ratio for TX1, time: 8:00-10:00

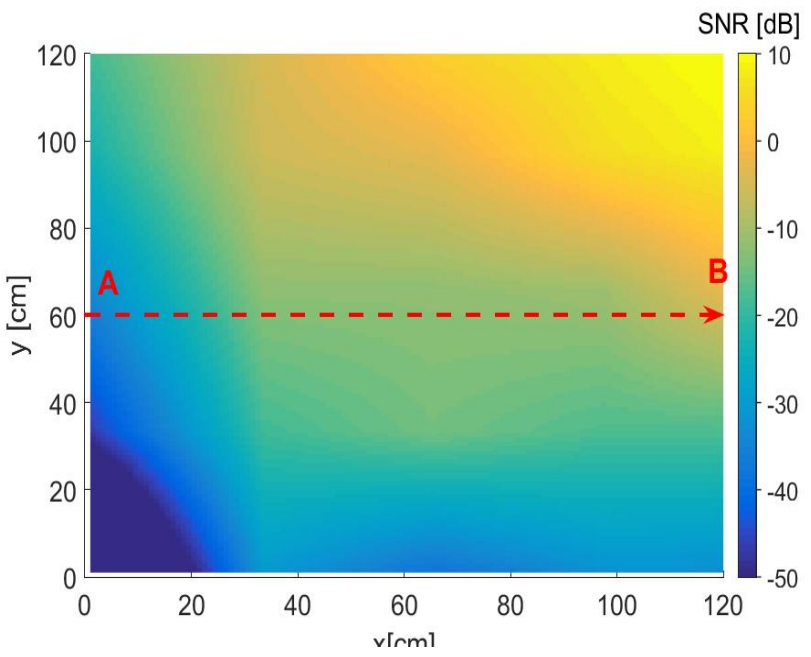

Figure 17: Averaged Measured Signal to Noise Ratio for TX1, time: 13:0015:00

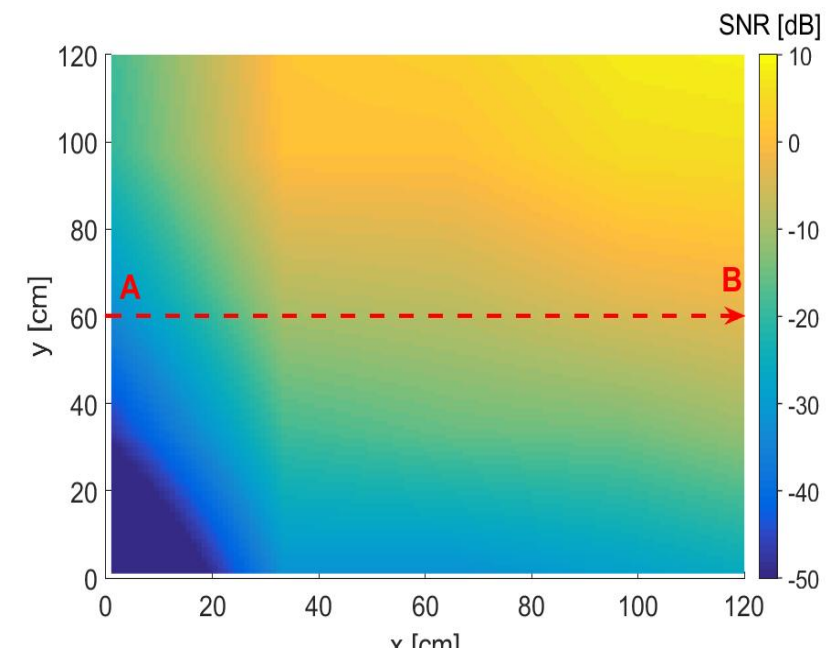

Figure 18: Averaged Measured Signal to Noise Ratio for TX1, time: 18:0020:00 transmitter, namely for low values of y coordinate, according to reference system in Fig. 14 and progressively increase in the region near illuminating lamp.A sensible variation of measured SNR can be appreciated at different times the day. Indeed, the height of the sun and its position with respect to the windows of the office room, significantly affect overall interference. Similar results in terms of SNR amplitude have been measured for the other transmitters but are not shown for the sake of space. Obviously, SNR distribution on the xy plane changes according to transmitter position. In these conditions, positioning error has been calculated. In order to properly validate the correctness of measurements, averaged values between measures taken each 15 minutes, have been considered for each session and shown in Fig. 19, 20 and 21, considering the path between point $A=[0,60,0] \mathrm{cm}$ and point $B=[120,60,0] \mathrm{cm}$.

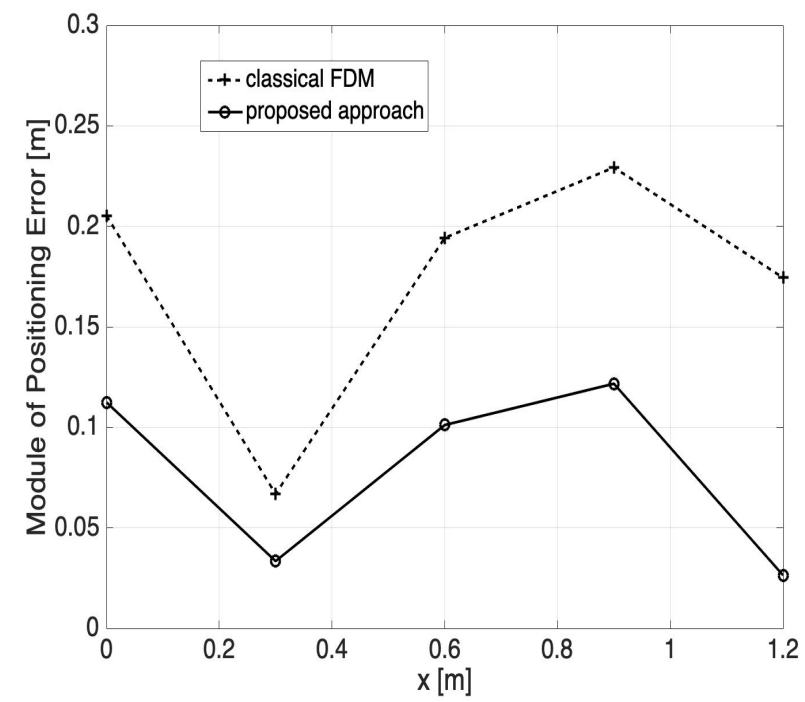

Figure 19: Average error of proposed VLC indoor positioning system in the path from the point $A=[0,60,0] \mathrm{cm}$ to the point $B=[120,60,0] \mathrm{cm}$, time: $8: 00$ 10:00

It is evident how, even in extremely hard noisy conditions, proposed noise aware approach significantly mitigates error positioning in respect to the classical FDM-RSSI approach, allowing the possibility of using indoor positioning based on VLC also in real use case where a high SNR is not achievable due to disturbing sunlight, and other error sources. These results can be also exploited in environments where transmitted illuminating power is strictly regulated, not only for eye safety, but also for practical motivations (e.g. light monitoring in greenhouses).

\section{Conclusions and future works}

A low cost indoor positioning system, based on a real time monitoring of environmental noise, has been proposed in this work. Low cost equipment has been used in our architecture and a competitive accuracy, in comparison with a classical FDM-RSSI without noise awareness integrated, has been performed. The proper manipulation of measured received power spectral density inside frequency ranges allocated for 


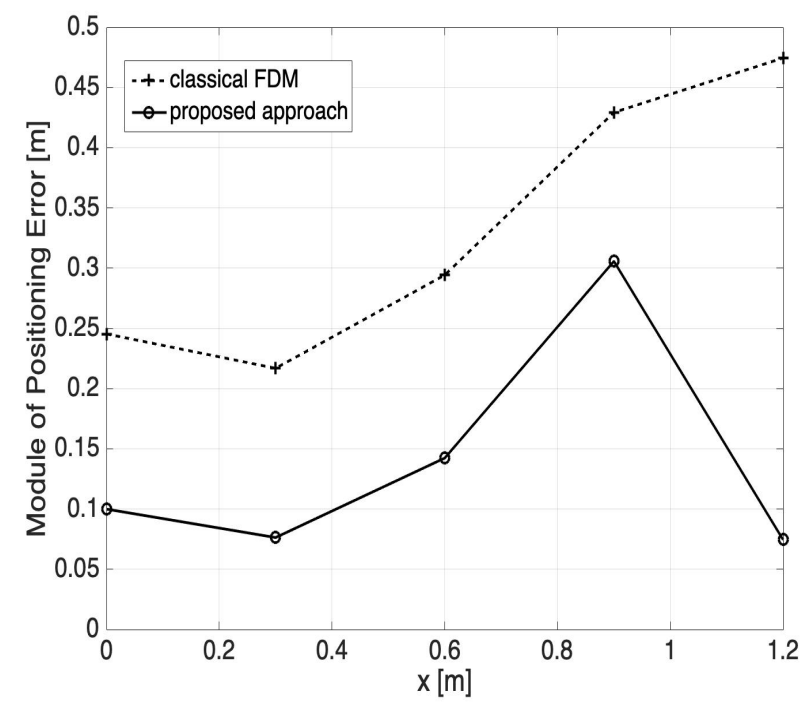

Figure 20: Average error of proposed VLC indoor positioning system in the path from the point $A=[0,60,0] \mathrm{cm}$ to the point $B=[120,60,0] \mathrm{cm}$, time: $13: 00$ 15:00

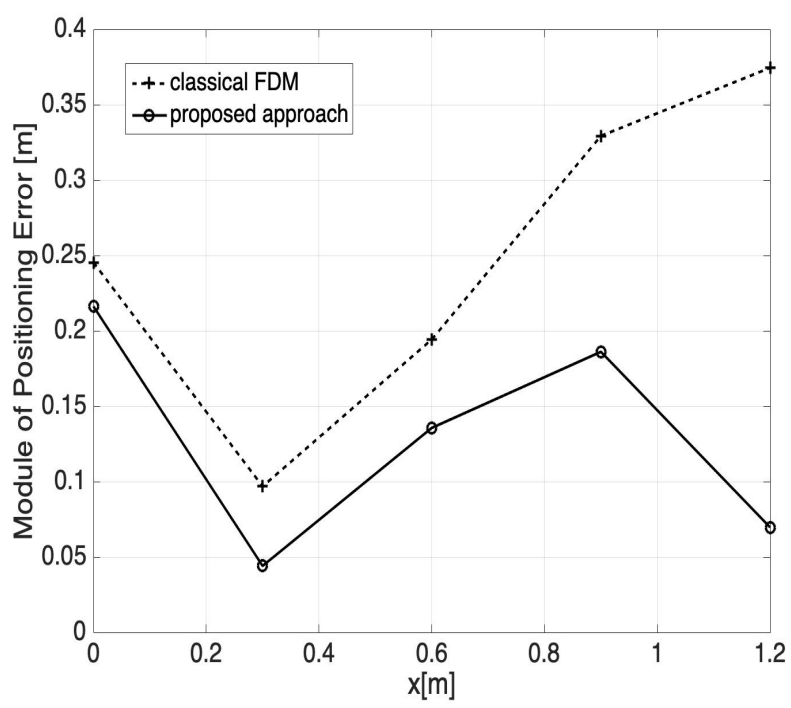

Figure 21: Average error of proposed VLC indoor positioning system in the path from the point $A=[0,60,0] \mathrm{cm}$ to the point $B=[120,60,0] \mathrm{cm}$, time: $18: 00$ 20:00
LED transmissions, and outside these ranges for environmental noise, represents a novel way to face the problem of disturbing signals in the scenario, mainly due to sunlight, which represents the main problem to a wide diffusion of indoor positioning system based on visible light. Numerical simulations have been carried out and experimental results on a $2 \mathrm{D}$ grid of $1.20 \mathrm{~m}$ $\mathrm{x} 1.20 \mathrm{~m}$ illuminated low power LEDs, have been performed, achieving an high accuracy in the main area of the scenario under analysis and a significant compensation in peripheral areas, where Signal to Noise values are lower. No hybrid architecture or auxiliary devices have been considered nor in the model, neither in the experimental setup. A further extension of this work will deal with the integration of the effects of multi-path in the channel model. In addition, the application of the model will be improved through a solid statistical analysis, including the effect of different positioning algorithm on our approach.

\section{References}

[1] S. Dimitrov, H. Haas, Principles of LED Light Communications: Towards Networked Li-Fi, Cambridge University Press, 2015.

[2] C. Wang, H. Yu, Y. Zhu, A long distance underwater visible light communication system with single photon avalanche diode, IEEE Photonics Journal 8 (5) (2016) 1-11. doi:10.1109/JPHOT.2016.2602330.

[3] S. Pergoloni, Z. Mohammadi, A. Vegni, Z. Ghassemlooy, M. Biagi, Metameric indoor localization schemes using visible lights, Journal of Lightwave Technology 35 (14) (2017) 2933-2942. doi:10.1109/JLT.2017.2706527.

[4] M. Biagi, S. Pergoloni, A. Vegni, Last: a framework to localize, access, schedule and transmit in indoor vlc systems, Journal of Lightwave Technology 33 (9) (2015) 1872-1877.

[5] A. Vegni, M. Biagi, An indoor localization algorithm in a small-cell ledbased lighting system, in: Conf. on Indoor Positioning and Indoor Navigation (IPIN), 2012

[6] Y. Gu, A. Lo, I. Niemegeers, A survey of indoor positioning systems for wireless personal networks, IEEE Communications Surveys Tutorials 11 (1) (2009) 13-32. doi:10.1109/SURV.2009.090103.

[7] A. Harter, A. Hopper, A distributed location system for the active office, IEEE Network 8 (1) (1994) 62-70. doi:10.1109/65.260080.

[8] P. Bahl, V. N. Padmanabhan, Radar: an in-building rf-based user location and tracking system, in: Proceedings IEEE INFOCOM 2000. Conference on Computer Communications. Nineteenth Annual Joint Conference of the IEEE Computer and Communications Societies (Cat. No.00CH37064), Vol. 2, 2000, pp. $775-784$ vol.2. doi:10.1109/INFCOM.2000.832252.

[9] S. Costanzo, G. D. Massa, A. Costanzo, L. Morrone, A. Raffo, F. Spadafora, A. Borgia, G. Formetta, G. Capparelli, P. Versace, Lowcost radars integrated into a landslide early warning system, in: Advances in Intelligent Systems and Computing.

[10] S. Costanzo, G. D. Massa, A. Costanzo, A. Borgia, A. Raffo, G. Viggiani, P. Versace, Software-defined radar system for landslides monitoring, in: Advances in Intelligent Systems and Computing.

[11] P. Prasithsangaree, P. Krishnamurthy, P. Chrysanthis, On indoor position location with wireless lans, in: The 13th IEEE International Symposium on Personal, Indoor and Mobile Radio Communications, Vol. 2, 2002, pp. 720-724 vol.2. doi:10.1109/PIMRC.2002.1047316.

[12] J. Hallberg, M. Nilsson, K. Synnes, Positioning with bluetooth, in: 10th International Conference on Telecommunications, 2003. ICT 2003., Vol. 2, 2003, pp. 954-958 vol.2. doi:10.1109/ICTEL.2003.1191568.

[13] C. Wang, Z. Shi, F. Wu, J. Zhang, An rfid indoor positioning system by using particle swarm optimization-based artificial neural network, in: 2016 International Conference on Audio, Language and Image Processing (ICALIP), 2016, pp. 738-742. doi:10.1109/ICALIP.2016.7846624.

[14] S. Costanzo, A. Costanzo, A. Raffo, A. Borgia, Environmental effects on the performances of a uhf passive tag-based commercial rfid system, in: New Advances in Information Systems and Technologies. 
[15] T. Kitasuka, K. Hisazumi, T. Nakanishi, A. Fukuda, Wips: Location and motion sensing technique of ieee 802.11 devices, in: Third International Conference on Information Technology and Applications (ICITA'05), Vol. 2, 2005, pp. 346-349. doi:10.1109/ICITA.2005.312.

[16] D. Karunatilaka, F. Zafar, V. Kalavally, R. Parthiban, Led based indoor visible light communications: State of the art, IEEE Communications Surveys Tutorials 17 (3) (2015) 1649-1678. doi:10.1109/COMST.2015.2417576.

[17] J. Armstrong, Y. A. Sekercioglu, A. Neild, Visible light positioning: a roadmap for international standardization, IEEE Communications Magazine 51 (12) (2013) 68-73. doi:10.1109/MCOM.2013.6685759.

[18] Y. Zhuang, L. Hua, L. Qi, J. Yang, P. Cao, Y. Cao, Y. Wu, J. Thompson, H. Haas, A survey of positioning systems using visible led lights, IEEE Communications Surveys Tutorials PP (99) (2018) 1-1. doi:10.1109/COMST.2018.2806558.

[19] U. Nadeem, N. U. Hassan, M. A. Pasha, C. Yuen, Indoor positioning system designs using visible led lights: performance comparison of tdm and fdm protocols, Electronics Letters 51 (1) (2015) 72-74. doi:10.1049/el.2014.1668.

[20] H. S. Kim, D. R. Kim, S. H. Yang, Y. H. Son, S. K. Han, An indoor visible light communication positioning system using a rf carrier allocation technique, Journal of Lightwave Technology 31 (1) (2013) 134-144. doi:10.1109/JLT.2012.2225826.

[21] M. Yasir, S. W. Ho, B. N. Vellambi, Indoor positioning system using visible light and accelerometer, Journal of Lightwave Technology 32 (19) (2014) 3306-3316. doi:10.1109/JLT.2014.2344772.

[22] R. Zhang, W. D. Zhong, K. Qian, D. Wu, Image sensor based visible light positioning system with improved positioning algorithm, IEEE Access 5 (2017) 6087-6094. doi:10.1109/ACCESS.2017.2693299.

[23] A. Costanzo, V. Loscri, Demo: A Context Aware Algorithm for an Adaptive Visible Light Communication System, in: EWSN 2018 - International Conference on Embedded Wireless Systems and Networks , Madrid, Spain, 2018

URL https : //hal .inria.fr/hal-01686565

[24] A. Costanzo, V. Loscri, S. Costanzo, Adaptive Dual Color Visible Light Communication (VLC) System, in: 6th World Conference on Information Systems and Technologies, Napoli, Italy, 2018.

URL https: //hal.inria.fr/hal-01687543

[25] G. Cossu, M. Presi, R. Corsini, P. Choudhury, A. M. Khalid, E. Ciaramella, A visible light localization aided optical wireless system, in: 2011 IEEE GLOBECOM Workshops (GC Wkshps), 2011, pp. 802-807. doi:10.1109/GLOCOMW.2011.6162565.

[26] C. Huang, X. Zhang, Los-nlos identification algorithm for indoor visible light positioning system, in: 2017 20th International Symposium on Wireless Personal Multimedia Communications (WPMC), 2017, pp. 575-578. doi:10.1109/WPMC.2017.8301878.

[27] A. Norrdine, An algebraic solution to the multilateration problem, in: International Conference on Indoor Positioning and Indoor Navigation, 2012. 